\title{
INTERAÇÃO CIENTÍFICO-SOCIAL: CONTRIBUIÇÕES AO CONHECIMENTO E SAÚDE DOS PROFISSIONAIS EM TEMPOS DE COVID 19
}

\author{
Alciene P. da Silva ${ }^{1}$; Joana C. Bernhard' ${ }^{1}$; Nastassja S. M. de Souza' ${ }^{1}$; Dirce S. \\ Backes $^{2}$; Silomar Ilha ${ }^{2}$
}

\section{Resumo:}

Profissionais da saúde estão sendo impactados psicologicamente, apresentando sintomas de ansiedade e níveis de estresse aumentados, como consequência da pandemia por COVID 19, o que denota a necessidade de auxiliá-los, de alguma forma, nesse processo. O objetivo deste trabalho foi relatar experiência na efetivação de uma proposta de construção de intervenção para profissionais da saúde que estão na linha de frente da COVID 19. Trata-se de relato de experiência, elaborado na disciplina integração científico social, do mestrado em ciências da saúde da Universidade Franciscana (UFN) do Rio Grande do Sul. A atividade foi desenvolvida com base em oito etapas propostas na pesquisa-ação: Identificação do problema dentro do contexto, levantamento dos dados pertinentes, análise dos dados levantados, significação dos dados levantados, identificação da necessidade de mudança, encontrando possíveis soluções, intervenção ação, transformação. Este trabalho permitiu a elaboração de uma cartilha educacional, visando contribuir para o conhecimento e a promoção do cuidado com a saúde mental e física dos profissionais, especialmente no período pandêmico.

Palavras-chave: atividade física; saúde mental; trabalhador da saúde.

Eixo Temático: Atenção Integral e Promoção à Saúde (AIPS).

\section{INTRODUÇÃO}

Os primeiros casos de Corona Virus Disease 2019 (COVID-19) foram notificados em março de 2020 na China, com o primeiro caso da doença identificado no Brasil em 25 de fevereiro de 2020. No entanto, desde dezembro de 2019 o mundo já discutia a doença causada pelo novo coronavírus e muitas incertezas surgiram naquele momento (DANTAS et al., 2021). Com o avanço da pandemia, os serviços de saúde foram sobrecarregados, e os números de casos aumentaram exponencialmente. Diante deste cenário, sentimento de insegurança e medo entre os profissionais da saúde foram observados, especialmente entre os profissionais que estão na linha de frente no combate ao COVID-19 (BARROS et al., 2020). Com medidas de segurança mais rígidas impostas à população, a quarentena também 
gerou sintomas de estresse pós-traumático, sentimento de confusão e raiva. A população em geral, e especialmente os profissionais de saúde, apresentaram repercussão negativa na saúde mental e relataram sentimentos de desesperança, desespero, medo da morte, sentimento de culpa em transmitir o vírus aos seus familiares e contatos próximos (DANTAS et al., 2021).

Para entender melhor a natureza humana e os seus sentimentos diante de algo trágico, a logoterapia (psicoterapia do sentido), criada por Viktor Emil Frankl (FRANKL, 2005), apresenta uma visão de ser humano em que ele denomina de dimensões antropológicas: a) físico = corpo, b) psíquico = mente, e d) espírito. Nesse sentido, ver o ser humano do ponto de vista antropológico, é entender que o homem não é um animal que reage de forma instintiva, mas é um ser que tem liberdade de escolha e de responsabilidade sobre estas, ou seja, não somos meras vítimas das circunstâncias, podemos e devemos ter uma atitude firme em prol da vida em qualquer situação (FRANKL, 2017).

Frankl (2017) afirma que todo ser humano, pode encontrar sentido em toda e qualquer circunstância de sua vida. Com base em seus estudos e experiência, ele ensina que, fatalmente, o sere humanos tem que enfrentar o que ele chama de "tríade trágica": I. sofrimento, II. a culpa e III. a morte. A questão não é evitar essa tríade, mas saber lidar com esses sentimentos e de outras situações que não estão sob controle. Quando se tem claro o sentido da vida em cada momento, mesmo e principalmente em momentos de tragédia, ou de calamidade como a que a sociedade está vivenciando por conta da COVID-19, é possível encontrar sentido (força espiritual) para superar esse momento, e como bem lembra Frankl, parafraseado Nietzsche: “Quem tem um 'porquê' de viver pode suportar qualquer 'como'”.

Visto a crise pandêmica produzida pela COVID-19, faz-se necessário pensar nos sentimentos presentes nos profissionais da saúde que estão trabalhando na linha de frente da pandemia, e que estão sobrecarregados tanto fisicamente quanto mentalmente. Tal situação pode acarretar problemas ao bem-estar e qualidade de vida destes profissionais e refletir em uma carga emocional negativa, interferindo tanto nas atividades laborais quanto na funcionalidade desses indivíduos. Faz-se necessário, 
ainda, produzir materiais e/ou estratégias que com objetivo de auxiliar os profissionais nesse contexto.

Diante desse contexto, o objetivo deste estudo foi relatar a experiência na efetivação de uma proposta de construção de intervenção para profissionais da saúde que estão na linha de frente da COVID-19.

\section{METODOLOGIA}

Trata-se de um relato de experiência, de uma atividade desenvolvida, no período de março a julho de 2021, na disciplina de Interação Científico-Social, pertencente ao Mestrado em Ciências da Saúde e da Vida da Universidade Franciscana (UFN), da cidade de Santa Maria, no Rio Grande do Sul (RS), Brasil.

A disciplina interação científico-social, tem por objetivos: Proporcionar vivência teórico-prática na comunidade, a partir de referenciais teórico-metodológicos interativos e participativos; possibilitar a vivência do aluno na comunidade através do acompanhamento de ações extensionistas de projetos institucionais; vincular o projeto de pesquisa do aluno com uma atividade de saúde na comunidade e elaborar relatório sobre a atividades realizada na comunidade e apresentar em forma de seminários integrativos.

Nos três primeiros encontros da disciplina, os docentes mediaram discussões sobre o referencial teórico e metodológico da disciplina, por meio de leituras de conceitos sistêmicos e sobre a metodologia da pesquisa-ação, como propositiva de intervenções no cotidiano profissional e social dos seres humanos. Para tanto, os professores organizaram metodologicamente o processo de trabalho da disciplina em oito etapas: I- Identificação do problema dentro do contexto, II- levantamento dos dados pertinentes, III- análise dos dados levantados, IV- significação dos dados levantados, V- identificação da necessidade de mudança, VI- encontrando possíveis soluções, VII- intervenção ação, VIII- transformação (KOERICH et al., 2009).

Durante o semestre, os mestrandos foram divididos em duplas ou trios, de livre escolha e, a cada encontro da disciplina, os mesmos eram orientados, de forma gradativa, ao desenvolvimento de uma ou mais etapas metodológicas, as quais eram apresentadas ao grande grupo (colegas do mestrado e professores) na aula 
subsequente. No momento das apresentações, o grupo era estimulado a emitir opinião acerca do trabalho desenvolvido em cada etapa, de forma a promover uma discussão, sinalizando sugestões, críticas construtivas, elogios e tudo que pudesse contribuir para a efetividade e bom desempenho da atividade.

Ao final da disciplina, realizou-se um seminário para a socialização final do trabalho desenvolvido por cada dupla ou trio, a partir do atendimento integral das oito etapas propostas.

\section{RESULTADOS E DISCUSSÃO}

A disciplina interação científico-social, por sua natureza prevê a interação entre a academia (universidade) e a sociedade. Para tanto, são propostas metodologias de trabalho intervencionistas. No primeiro semestre do ano de 2021, foi desenvolvida uma atividade em oito etapas, adaptadas da pesquisa-ação, propostas por Koerich et al (2009), as quais serão detalhadas a seguir:

$\mathrm{Na}$ primeira, "identificação do problema dentro do contexto", os mestrandos foram desafiados a eleger um objeto de trabalho de acordo com o contexto atual. Ou seja, exercer a proatividade de autonomia no delineamento do contexto a ser trabalhado. Nessa etapa, as autoras desse trabalho, compreenderam que com os desafios e incertezas que surgiram no período da pandemia da COVID-19, os profissionais da saúde tiveram que se adaptar aos novos protocolos de atendimento, trabalhar com escassez de materiais e leitos de internação hospitalar, especialmente leitos de terapia intensiva. Diante do cenário, é possível que tenham surgido sentimentos como medo e a preocupação com a contaminação pelo vírus e a transmissão aos seus familiares.

Assim, as pesquisadoras, delimitaram como "problema" dentro do contexto, o impacto psicológico, com sintomas de ansiedade e níveis de estresse aumentados em profissionais da saúde como consequência da pandemia da COVID-19. Após a discussão em sala de aula, foram orientadas a etapa dois, por meio do "levantamento dos dados pertinentes". Nessa etapa, as mestrandas precisaram buscar informações sobre a suposição inicial, com vistas a confirmar se o problema dentro do contexto elegido pelas mesmas na etapa 1 se efetivava ou não na prática dos profissionais. 
Para tanto, as pesquisadoras encaminharam, de forma aleatória, um formulário disposto pelo google para profissionais da saúde de diferentes estados, obtendo retorno de 40 profissionais de seis estados do Brasil: Bahia (Ilhéus, Itabuna, Salvador), Pernambuco (Recife), Piauí (Teresina), São Paulo (SP - capital), Paraná (Curitiba) e Rio Grande do Sul (Santa Maria).

Após, procedeu-se a terceira etapa, "análise dos dados levantados". Nesse momento as mestrandas buscaram analisar as respostas dos questionários online e compreender as principais vivências e sentimento produzidos pela pandemia nos profissionais da saúde. Para sustentar a construção do formulário e a análise do mesmo, as autoras embasaram-se na Tríade-Trágica de Viktor Frankl, identificando a presença de sentimentos de sofrimento, culpa e morte, relacionados ao momento pandêmico, buscando, ainda, a identificação dos motivos da presença dos referidos sentimentos (FRANKL, 2005). Na compreensão de Frankl, a Tríade Trágica: sofrimento, culpa e morte é uma constatação da condição humana de estar-nomundo. Percebida pelo ser humano que vive em constante busca de sentido, sendo esse o momento em que poderá deparar-se com os sentimentos de sofrimento, culpa e morte (ZALESKI; VIETTA, 1996).

Observou-se, nesse contexto, que $67,5 \%$ dos profissionais referiram 0 sentimento de medo relacionada à pandemia atual. Também foi identificado que apenas 55\% dos indivíduos praticava alguma atividade física, sendo uma taxa de baixa adesão. Na quarta etapa proposta na atividade, "significação dos dados levantados", buscou-se identificar os fatores associados ao sentimento de medo apontado pelos participantes, momento em que se identificou cinco fatores principais: morte, irresponsabilidade da população, incompetência no gerenciamento da doença, contaminação e gravidade da doença, com destaque para o medo de morte (13 respostas) e a contaminação (12 respostas) como principais fatores contribuintes para tal sentimento.

A partir das etapas supracitadas, as mestrandas foram desafiadas a quinta etapa que consistem na "identificação das necessidades de mudança". Assim, diante da análise das informações obtidas, verificou-se a necessidade de auxiliar as pessoas no que se refere ao sentimento de medo e sofrimento, pois compreende-se que tais 
sentimentos prejudicam a saúde mental e contribuem para a intensificação de sentimentos persistentes de forma negativa.

Na sequência, deu-se início a sexta etapa, denominada por: "encontrando possíveis soluções". Através de uma discussão entre as pesquisadoras, foram levantadas possíveis propostas que pudessem contribuir de alguma forma para conscientização e incentivo de manter uma boa saúde mental e física nestes profissionais. Inicialmente surgiu a ideia de realizar uma oficina em modo online, em que as pesquisadoras pudessem realizar uma conversa mais próxima com os profissionais e assim promover uma interação e debate sobre a temática da saúde mental e importância do cuidado.

As oficinas se caracterizam pela construção participativa, onde existe troca de experiência e de conhecimento pelos participantes. O pesquisador atua como facilitador do processo e direcionar os trabalhos, os quais podem ser precedidos da elaboração de material ou ser construído pelos próprios participantes (CAMARGO; FERRARI, 2009). Entretanto, em decorrência do momento vivenciado pela pandemia por COVID-19, a carga de trabalho dos profissionais está aumentada e, compreendese a necessidade do descanso diário que deve ser preservado.

Diante disso, tendo em vista não interromper o trabalho e nem o lazer destes profissionais, surgiu a ideia de criar uma cartilha educacional, em que pudesse se compartilhar de forma didática, informações sobre como manter uma saúde mental positiva, assim como a saúde física. As cartilhas, carcaterizam-se como materiais educativos, como meio de comunicação, onde o conteúdo contido nelas reflete situações da sociedade (COLLARES, 2011).

Após a discussão em sala de aula e aprovação da ideia pelo grande grupo, iniciou-se a construção da mesma, atendendo ao início da sétima etapa do processo, denominada de "intervenção-ação", A cartilha, foi elaborada e, como eixo central, considerou-se a atividade física, já que ela foi identificada como presente em pouco mais da metade dos profissionais da saúde.

Sabe-se que o interesse da atividade física no campo da saúde mental vem crescendo cada vez mais, em vista de todos os benefícios que a prática regular trás ao indivíduo. Então buscou-se abordar, inicialmente, a diferença entre a atividade 
física e o exercício físico de modo sistemático, e a quantidade de atividade física semanal é necessária para o indivíduo se beneficiar com a prática regular, visto que segundo a Organização Mundial da Saúde, para o indivíduo adquirir todos os benefícios à sua saúde física e mental, estes devem quantificar um tempo mínimo semanal para obter esses efeitos favoráveis (OMS, 2020).

Aproveitando o contexto do exercício físico, foram apresentadas, de forma didática e exemplificada com imagens, possibilidades de exercícios de alongamento para os indivíduos realizarem tanto em casa como em seus ambientes ocupacionais, uma vez que a atividade física laboral tem grande importância no contexto ocupacional, beneficiando os trabalhadores e evitando problemas constantes como Lesões por Esforços Repetitivos (LER) e Distúrbios Osteomusculares Relacionados ao Trabalho (DORT) (ASSUNÇÃO; ABREU, 2017).

Além disso, foram descritos e explicados os quatro neurotransmissores (endorfina, serotonina, dopamina e oxitocina) importantes e com grande potencial na nossa saúde mental e física. Como referência, utilizou-se a cartilha "a química das emoções" disposta online pelo Conselho Regional de Química (CRQ,2020). Através dessa, foi disposta informações sobre esses neurotransmissores, como eles atuam no nosso corpo, e formas naturais de aumentarmos sua expressão.

A escolha da inclusão desse tópico se justifica pelo fato de que o aumento desses neurotransmissores está ligado a uma saúde mental positiva, assim como a saúde física. Nesse sentido, as formas naturais de produção do neurotransmissores são exemplificadas na cartilha e refletem a relevância da atividade física, assim como a contribuição de atividades cotidianas e de lazer, como ouvir músicas, ter um hobbie, alimentar-se, se expor ao sol, entrar em contato com a natureza, diminuir o estresse, entre tantos outros exemplos citados na cartilha.

Por fim, apresentou-se conteúdo referente a morte, pois a mesma durante séculos, foi considerada um acontecimento natural, esperado, propiciando ao homem a possibilidade de morrer em sua própria casa, entre familiares e amigos. O temor da morte inesperada que vem se apresentando pela COVID-19 e que tem sido devastadora na vida de milhares de famílias e na vivencia de profissionais de saúde em todo mundo (ARIÈS, 2000). 
Com a impossibilidade de uma ação-intervenção de modo presencial, em decorrência da pandemia por COVID 19, após a elaboração da cartilha, a mesma foi enviada no documento em versão pdf para os 40 profissionais da saúde participantes da etapa dois do processo de trabalho. Junto ao e-mail enviado com a cartilha, as pesquisadoras solicitaram como uma forma de obter um feedback, que os profissionais, assim que possível, retornassem por e-mail a sua opinião sobre o material elaborado e disponibilizado a eles. Um total de 11 profissionais retornaram com o feedback positivo, confirmando a oitava etapa (transformação) proposta na pesquisa.

\section{CONCLUSÃO}

O desenvolvimento deste trabalho permitiu constatar a grande presença do medo e do sofrimento nos profissionais da saúde, muito atribuído ao medo da morte e da contaminação, tanto sua quanto das pessoas que convivem. Os profissionais estão constantemente expostos em ambientes com preditores negativos de saúde, convivendo com o sofrimento do outro, a morte, exaustão física e mental, a angústia, o estresse, entre outros fatores. Assim, percebemos como este público deve ter uma atenção especial, afinal, estes profissionais em ambiente ocupacional promovem o cuidado do outro, mas quem cuida destes?

Ao propor proposta a elaboração de uma cartilha educativa, voltada a estes profissionais, com a ideia de promover hábitos saudáveis, pode-se perceber o quanto é importante a realização destas iniciativas, de conhecer a realidade dos indivíduos, o que os afeta, e como eles recebem algo criado especificamente para eles, demonstrando sua importância como profissional da saúde e de como eles devem ter um cuidado especial com sua saúde mental para seu pleno bem-estar.

Por meio da cartilha informativa, foram propostas atividades de mudança de hábitos de vida, como a prática de atividade física, yoga e dança como maneira de melhoria da saúde como um todo e também da saúde mental. Desse modo, o trabalho permitiu detectar os principais sentimentos relatados pelos profissionais da saúde e por meio de cartilha informativa propor mudanças para contribuir com seu bem-estar, que foram recebidas de modo positivo pelos participantes. 


\section{REFERÊNCIAS}

ARIĖS, P. O homem diante da morte. Tradução Luiza Ribeiro. 2. ed. Rio de Janeiro: Francisco Alves. 2000. v. 1, 310p.

ASSUNÇÃO A.A, ABREU M.N.S. Fatores associados a distúrbios osteomusculares relacionados ao trabalho autorreferidos em adultos brasileiros. Rev Saude Publica. 2017;51 Supl 1:10s. Disponível em: https://www.scielo.br/j/rsp/a/BYg5wVdtqqjDTh6jHQpngRx/?lang=en\#. Acesso: 09.09.2021.

BARROS, Marilisa Berti de Azevedo et al. Relato de tristeza/depressão, nervosismo/ansiedade e problemas de sono na população adulta brasileira durante a pandemia de COVID-19. Epidemiologia e Serviços de Saúde [online]. 2020, v. 29, n. 4 [Acessado 13 Setembro 2021] , e2020427. Disponível em: <https://doi.org/10.1590/S1679-49742020000400018>. Epub 24 Ago 2020. ISSN 2237-9622. https://doi.org/10.1590/S1679-49742020000400018. Acesso: 13.09.2021.

CAMARGO, E.A.I.; FERRARI, R.A.P. Adolescentes: conhecimentos sobre sexualidade antes e após a participação em oficinas de prevenção. Ciênc saúde coletiva. V.14, n.3, p. 937-46, 2009. Disponível em: http://www.scielo.br/pdf/csc/v14n3/30.pdf Acesso: 13.09. 2021.

COLLARES, S. A. O. O uso da cartilha progressiva (1907) nas escolas do estado do Paraná. In: XXVI Simpósio Nacional de História - ANPUH. São Paulo, 2011. http://www.snh2011.anpuh.org/resources/anais/14/1300672839_ARQUIVO_textoanpuh.pdf. Acesso: 13.09. 2021.

CONSELHO FEDERAL DE QUIMICA (CFQ). Cartilha: A quimica das emoções. 2020. Disponível em: http://cfq.org.br/wp-content/uploads/2021/01/CartilhaQu\%C3\%ADmica-das-Emo\%C3\%A7\%C3\%B5es-1.pdf. Acesso: 10.09.2021. 
DANTAS, Eder Samuel Oliveira. Saúde mental dos profissionais de saúde no Brasil no contexto da pandemia por Covid-19. Interface - Comunicação, Saúde, Educação [online]. 2021, v. 25, suppl 1 [Acessado 13 Setembro 2021] , e200203. Disponível em: <https://doi.org/10.1590/Interface.200203>. Epub 08 Jan 2021. ISSN 1807-5762. https://doi.org/10.1590/Interface.200203.Acesso: 13.09. 2021.

FRANKL, V. E. Logoterapia e análise existencial. Tradução Jonas P. dos Santos. Campinas: Editorial Psy II, 2017. 303 p.

FRANKL, V. E. Um sentido para vida: psicoterapia e humanismo. 11. ed. Tradução Pe. Viktor Lapenta. Aparecida: Editora Santuário, 2005. 159 p.

Koerich MS, Backes DS, Sousa FGM de, Erdmann AL, Alburquerque GL. Pesquisaação: ferramenta metodológica para a pesquisa qualitativa. Rev. Eletr. Enferm. [Internet]. $1^{\circ}$ de junho de 2017 [citado 13ํ de setembro de 2021];11(3). Disponível em: https://revistas.ufg.br/fen/article/view/47234 Acesso: 13.09. 2021.

ORGANIZAÇÃO MUNDIAL DA SAÚDE. Diretrizes da OMS para atividade física e comportamento sedentário.

https://apps.who.int/iris/bitstream/handle/10665/337001/9789240014886por. pdf?sequence=102\&isAllowed=y\#: :text=Para\%20sa\%C3\%BAde\%20e\%20be m\%2Destar,dia\%20para\%20crian\%C3\%A7as\%20e\%20adolescentes Acesso em: 12 de jun, 2020.

SANTOS, D. M. B. Educação para sentido na vida e valores: percepção de universitários a partir do livro "Em busca de sentido", de Viktor Frankl. Revista Brasileira em Estudos de Pedagogia, v. 100, n. 254, p. 230-252, 2019.

ZALESKI, E. G. F.; VIETTA, E. P. O sentido da vida do portador da AIDS (síndrome da imunodeficiência adquirida): uma questão de saúde mental. Campo Grande: Editora UFMS, 1996. 181 p. 